\title{
Subcutaneous immunoglobulin for maintenance treatment in chronic inflammatory demyelinating polyneuropathy (PATH): a randomised, double-blind, placebo-controlled, phase 3 trial
}

Ivo N van Schaik, Vera Bril, Nan van Geloven, Hans-Peter Hartung, Richard A Lewis, Gen Sobue, John-Philip Lawo, Michaela Praus, Orell Mielke, Billie L Durn, David R Cornblath, Ingemar SJ Merkies, on behalf of the PATH study group*

\section{Summary}

Background Approximately two-thirds of patients with chronic inflammatory demyelinating polyneuropathy (CIDP) need long-term intravenous immunoglobulin. Subcutaneous immunoglobulin (SCIg) is an alternative option for immunoglobulin delivery, but has not previously been investigated in a large trial of CIDP. The PATH study compared relapse rates in patients given SCIg versus placebo.

Methods Between March 12, 2012, and Sept 20, 2016, we studied patients from 69 neuromuscular centres in North America, Europe, Israel, Australia, and Japan. Adults with definite or probable CIDP who responded to intravenous immunoglobulin treatment were eligible. We randomly allocated participants to $0.2 \mathrm{~g} / \mathrm{kg}$ or $0.4 \mathrm{~g} / \mathrm{kg}$ of a $20 \% \mathrm{SCIg}$ solution (IgPro20) weekly versus placebo ( $2 \%$ human albumin solution) for maintenance treatment for 24 weeks. We did randomisation in a 1:1:1 ratio with an interactive voice and web response system with a block size of six, stratified by region (Japan or non-Japan). The primary outcome was the proportion of patients with a CIDP relapse or who were withdrawn for any other reason during 24 weeks of treatment. Patients, caregivers, and study personnel, including those assessing outcomes, were masked to treatment assignment. Analyses were done in the intention-to-treat and per-protocol sets. This trial is registered with ClinicalTrials.gov, number NCT01545076.

Findings In this randomised, double-blind, placebo-controlled trial, we randomly allocated 172 patients: 57 (33\%) to the placebo group, $57(33 \%)$ to the low-dose group, and $58(34 \%)$ to the high-dose group. In the intention-to-treat set, 36 (63\% [95\% CI 50-74]) patients on placebo, 22 (39\% [27-52]) on low-dose SCIg, and 19 (33\% [22-46]) on high-dose $\mathrm{SCIg}$ had a relapse or were withdrawn from the study for other reasons $(\mathrm{p}=\mathbf{0} \cdot 0007)$. Absolute risk reductions were $25 \%$ (95\% CI 6-41) for low-dose versus placebo ( $\mathrm{p}=\mathbf{0} \cdot 007)$, 30\% (12-46) for high-dose versus placebo ( $\mathrm{p}=0.001)$, and $6 \%(-11$ to 23$)$ for high-dose versus low-dose $(\mathrm{p}=\mathbf{0} \cdot 32)$. Causally related adverse events occurred in $47(27 \%)$ patients (ten [18\%] in the placebo group, 17 [30\%] in the low-dose group, and 20 [34\%] in the high-dose group). Six (3\%) patients had 11 serious adverse events: one $(2 \%)$ patient in the placebo group, three $(5 \%)$ in the low-dose group, and two (3\%) in the high-dose group; only one (an acute allergic skin reaction in the low-dose group) was assessed to be causally related.

Interpretation This study, which is to our knowledge, the largest trial of CIDP to date and the first to study two administrations of immunoglobulins and two doses, showed that both doses of SCIg IgPro20 were efficacious and well tolerated, suggesting that SCIg can be used as a maintenance treatment for CIDP.

Funding CSL Behring.

\section{Introduction}

Chronic inflammatory demyelinating polyneuropathy (CIDP) is an acquired neuropathy with an assumed autoimmune pathogenesis. ${ }^{1}$ It runs a progressive, relapsing-remitting or monophasic course and can substantially limit patients' activity and participation, with decreased quality-of-life expectations. ${ }^{2}$ Intravenous immunoglobulin (IVIg) is a well established therapy for patients with the disease, with an estimated two-thirds needing these infusions over many years. ${ }^{3}$ Subcutaneous immunoglobulin (SCIg), an alternative route of immunoglobulin administration, has been used successfully in patients with primary immunodeficiency syndromes for more than 25 years. ${ }^{4}$ Systemic side-effects are reduced using SCIg compared with IVIg. In an open-label prospective study, ${ }^{5}$ the severity and frequency of headache and nausea were significantly reduced after SCIg infusions compared with IVIg infusions. Furthermore, haemolytic anaemia, which can be seen in IVIg therapy, can improve or disappear after a switch to SCIg. ${ }^{6}$ SCIg is absorbed into the bloodstream over 24-72 h, levelling out the sharp peak in serum IgG concentration that occurs immediately after an intravenous infusion.? Moreover, when the same total dose of IgG is given as four weekly SCIg infusions, rather than a single intravenous infusion each month, a near-steady-state
Lancet Neurol 2018; 17: 35-46 Published Online November 6, 2017 http://dx.doi.org/10.1016/ S1474-4422(17)30378-2

This online publication has been corrected.

The corrected version first appeared at thelancet.com/ neurology on December 15 2017

See Comment page 20

*Members listed at the end of the paper

Department of Neurology, Academic Medical Centre, University of Amsterdam Amsterdam, Netherlands (Prof I N van Schaik MD); Department of Medicine (Neurology), University Health Network, University of Toronto, Toronto, ON, Canada (Prof V Bril MD); Department of Biostatistics and Bioinformatics, Leiden University Medical Center, Leiden, Netherlands ( $\mathrm{N}$ van Geloven PhD); Department of Neurology, Medical Faculty, Heinrich Heine University, Düsseldorf, Germany (Prof H-P Hartung MD); Department of Neurology, Cedars-Sinai Medical Center Los Angeles, CA, USA (Prof RA Lewis, MD); Department of Neurology, Nagoya University Graduate School of Medicine, Nagoya, Japan (Prof G Sobue MD); CSL Behring, Marburg, Germany (J-P Lawo Diplom, M Praus Diplom, O Mielke MD); CSL Behring, King of Prussia, PA, USA (B L Durn BS); Department of Neurology, Johns Hopkins University School of Medicine, Baltimore, MD, USA (Prof D R Cornblath MD); and Department of Neurology, Maastricht University Medical Center, Maastricht, Netherlands (IS J Merkies MD) 


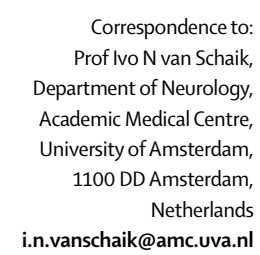

See Online for appendix
Research in context

\section{Evidence before this study}

We searched PubMed (from date of inception to Sept 26, 2017) with the search terms "subcutaneous immunoglobulin", "CIDP", and "clinical trial". No clinical trials investigating the efficacy, safety, and tolerability of subcutaneous immunoglobulin $(\mathrm{SClg})$ in chronic inflammatory demyelinating polyneuropathy (CIDP) had been published before the start of our study in March 12, 2012. Two case reports described seven patients who were successfully switched from intravenous immunoglobulin to SClg. Since the start of our study, two small placebo-controlled randomised trials have been published investigating SClg in patients with CIDP. Both trials showed promising results on impairment. A 1 year open-label follow-up study has suggested that $\mathrm{SClg}$ could be used as long-term maintenance treatment. Several open-label case series and one large prospective observational study have reported clinical efficacy and safety of weekly SClg.

\section{Added value of this study}

This is, to our knowledge, the first randomised trial that has studied two SClg doses in CIDP after IVIg stabilisation. This study showed that $\mathrm{SClg}$ can be used as a treatment for patients with CIDP. Our findings indicate that both doses are efficacious in maintaining patients and preventing relapse. Both doses of IgPro20 were well tolerated, with a good safety profile. The most frequently reported adverse events were local reaction at the infusion site; most of the local reactions were mild.

Implications of all the available evidence

The data from this study support a weekly subcutaneous dose of $0.2-0.4 \mathrm{~g} / \mathrm{kg}$. Maintenance SClg dose should be individualised on the basis of patient situation and previous intravenous immunoglobulin dose and frequency.
IgG concentration will be achieved that is $12-15 \%$ higher than the trough concentration after the IVIg infusion. ${ }^{8}$ These differences in pharmacokinetics probably explain the favourable systemic side-effect profile of SCIg compared with IVIg. ${ }^{79}$

SCIg infusions are well tolerated, efficacious, and preferred by many patients with primary immunodeficiency syndromes. ${ }^{10-12}$ SCIg increases patient autonomy and quality of life and leads to cost savings. ${ }^{13-16}$ Similar preference has been suggested in patients with CIDP receiving SCIg. ${ }^{17}$ However, the efficacy, safety, and tolerability of weekly SCIg have not been studied in an adequately powered, randomised clinical trial with appropriate disability outcome measures. ${ }^{18} \mathrm{We}$ hypothesised that the proportion of patients having a relapse or who are withdrawn from the study for any other reason would be reduced by SCIg as compared with placebo. Moreover, we wished to establish whether the effect was different with different SCIg doses, as most studies use a standard IVIg dose developed long ago for a different condition (immune thrombocytopenia). ${ }^{19}$ We investigated this hypothesis in a trial that compared two doses of SCIg IgPro20 (Hizentra; CSL Behring, Bern, Switzerland) with placebo for maintenance treatment of patients with CIDP.

\section{Methods}

\section{Study design and participants}

Patients were eligible if they were at least 18 years of age and had been diagnosed with definite or probable CIDP according to the European Federation of Neurological Societies/Peripheral Nerve Society (EFNS/PNS) 2010 criteria $^{20}$ and if they received their last IVIg treatment at least within 8 weeks before enrolment. Exclusion criteria were any polyneuropathy of other causes; any other disease that could cause neurological symptoms and signs or could interfere with treatment or outcome assessments severe conditions that could interfere with satisfactory conduct of the study; history of thrombotic episodes within 2 years before enrolment; known allergic or other severe reactions to blood products, including intolerance to previous IVIg, history of haemolysis after IVIg infusion, aseptic meningitis, recurrent severe headache, hypersensitivity, or severe generalised skin reaction; use of prohibited medication; a serum IgA concentration of less than $5 \%$ of the lower limit of normal; HIV or hepatitis B or C; abnormal laboratory variables; pregnancy or being a nursing mother; intention to become pregnant during the course of the study; and being a female patient of childbearing potential either not using or not willing to use a medically reliable method of contraception for the duration of the study. Full inclusion and exclusion criteria are provided in the appendix. All included patients gave written informed consent before study entry. The study protocol was approved by the ethics committees of all participating centres. The trial protocol has been published previously. $^{21}$

\section{Randomisation and masking}

We randomly allocated patients into three groups using an interactive voice and web response system maintained by Parexel (Berlin, Germany). Treatment allocation was in a 1:1:1 ratio with use of block randomisation with a block size of six, stratified by region (Japan or non-Japan). Access to the randomisation list was restricted to Parexel personnel not involved in the conduct or analysis of the trial.

All patients, caregivers, and study personnel, including those assessing outcomes, were masked and unaware of treatment assignment. We took standard measures for placebo and IgPro20 (eg, same container and closure system, storage conditions, colour, and foaming properties) to ensure adequate masking. We implemented a 
two-physician approach to reduce the chance of potential study unmasking. The treating physician was the primary contact for the patient and was responsible for all patientrelated questions, adverse event assessment, and all other study-related tasks. A second assessing physician was responsible for assessment of efficacy variables. The assessing physician did not have access to any data collected by the treating physician.

\section{Procedures}

After screening, all eligible patients progressed through three study periods: an IgG dependency test period (up to 12 weeks), an IVIg restabilisation period (up to 13 weeks), and a randomised subcutaneous treatment period ( 24 weeks of treatment with a final assessment at week 25; appendix). The IgG dependency test period was necessary to ensure that only patients who were still in need of IgG were randomly allocated. Only patients who were established to be IgG dependent were enrolled in the IVIg restabilisation period. In this period, patients received a 10\% IVIg solution (IgPro10 [Privigen; CSL Behring]) using the EFNS/PNS guideline-recommended dose of $2 \mathrm{~g} / \mathrm{kg}$ induction followed by $1 \mathrm{~g} / \mathrm{kg}$ every 3 weeks. ${ }^{20}$ We deemed standardised IVIg restabilisation necessary before initiation of placebo-controlled randomised subcutaneous treatment with IgPro20 or placebo. Only patients whose Inflammatory Neuropathy Cause and Treatment (INCAT) total score improved during the IVIg restabilisation period to at least the INCAT total score recorded at the screening visit, and who maintained a stable INCAT total score during the last 3 weeks of the restabilisation period, were eligible for randomisation.

During the subcutaneous treatment period, we calculated the total volume needed for all three treatment groups on the basis of bodyweight. We volume-matched all three treatments to high-dose volume requirement. One group received IgPro20 at $0.4 \mathrm{~g} / \mathrm{kg}$, one group received IgPro20 at $0.2 \mathrm{~g} / \mathrm{kg}$ plus placebo $(2 \%$ human albumin solution) to match volume, and one group received only placebo. We did the subcutaneous infusion of IgPro20 or placebo during 1 or 2 consecutive days in two sessions using infusion pumps, every week for 24 weeks. SCIg infusions were self-administered or administered by a caregiver at home, after site training. For monitoring of treatment compliance (appendix), patients had to fill out a drug accountability form, which was checked by the investigator and funder. Patients had to return all vials to the investigative site. We did a completion visit for all patients after completion of the subcutaneous treatment period or withdrawal for any reason during this period. We rescued patients who relapsed during the subcutaneous treatment period, within 1 week, with 10\% IVIg solution (IgPro10; 2 g/kg induction and $1 \mathrm{~g} / \mathrm{kg}$ maintenance) and discontinued them from the study after rescue. Patients had the option to enter an open-label extension study (NCT02027701) after completing the PATH study. The extension study has been completed and is currently being analysed.

\section{Outcomes}

The primary outcome was the proportion of patients who had a CIDP relapse or were withdrawn from the study for any reason during the 24 week subcutaneous treatment period. We defined a CIDP relapse as a deterioration (ie, increase) by at least 1 point in the total adjusted INCAT score (range 0 [healthy] to 10 [unable to make any purposeful movements with arms or legs] $)^{22}$ at any subcutaneous treatment period visit compared with baseline. We defined baseline scores as the scores assessed at the end of the IVIg restabilisation period.

Secondary outcomes for the subcutaneous treatment period were time to the primary endpoint, INCAT score, mean grip strength for both hands separately as assessed with use of the handheld Martin Vigorimeter, ${ }^{23}$ Medical Research Council sum score (range 0-80; including shoulder abduction, elbow flexion, wrist extension, index finger abduction, hip flexion, knee extension, foot dorsiflexion, and great toe dorsiflexion), ${ }^{24}$ and Inflammatory Neuropathy-Rasch-Built Overall Disability Scale (I-RODS; range 0 [most severe activity and social participation limitations] to 100 [no activity and social participation limitations]). ${ }^{25}$ We assessed INCAT scores, grip strength, Medical Research Council sum score, and I-RODS at screening, during the IgG dependency test period, before IVIg infusions during the IVIg restabilisation period, at baseline, at all visits during the subcutaneous treatment period including the completion visit (including for patients who had rescue therapy), and at any unscheduled visit. To assess safety and tolerability, we established adverse events per infusion and the number and percentage of patients with adverse events.

We also measured various exploratory outcomes. We assessed quality of life using the EuroQoL 5-Dimension Questionnaire, 14-item Treatment Satisfaction Questionnaire for Medication, and Work Productivity and Activity Impairment Questionnaire for General Health. ${ }^{26}$ The Treatment Satisfaction Questionnaire for Medication captures ease of use on a 7 point scale, ranging from extremely difficult to extremely easy. We assessed patient's preference with a questionnaire at the end of the study. Furthermore, we measured serum IgG trough concentrations (before administration of study drug). We also assessed the effect of IgPro20 on nerve conduction. All outcomes for the two prerandomisation periods and rescue treatment and other exploratory outcomes (Work Productivity and Activity Impairment Questionnaire for General Health and effect of IgPro2 on nerve conduction) will be reported separately.

\section{Statistical analysis}

We based sample size calculation on the null hypothesis that the proportion of patients relapsed or withdrawn during subcutaneous treatment would be equal in all 
groups and the alternative hypothesis that at least one of the SCIg dose groups would have a lower proportion than would the placebo group. We assumed that the proportion of patients who reached the primary endpoint would be $35 \%$ for the high dose, $52 \%$ for the low dose, and $65 \%$ for placebo. ${ }^{21}$ We based these numbers on data from the ICE study $^{22}$ extension period. Using the exact CochranArmitage trend test with equally spaced scores and a onesided significance level of $0 \cdot 025$, a sample size of 58 was needed in each treatment group to achieve a power of $90 \%$ in an intention-to-treat analysis on the basis of the above assumptions. Accounting for patients who would not pass the IgG dependency test and IVIg restabilisation period, we expected that 350 patients would need to be screened to ensure that 174 patients were randomly allocated.

We used the exact Cochran-Armitage trend test for the primary outcome to test for a trend over the three trial arms at a one-sided type I error of $0 \cdot 025$. If the hypothesised superiority could be shown, one-sided Fisher's exact tests were to be used for the subsequent pairwise comparisons: placebo versus low-dose IgPro20, placebo versus high-dose IgPro20, and low-dose versus high-dose IgPro20. We calculated the proportions and corresponding two-sided
95\% Wilson score CIs for each treatment group. We calculated point estimates for the difference in proportions and the corresponding exact two-sided $95 \%$ CIs for all pairwise treatment comparisons. Three prespecified sensitivity analyses with modified primary endpoint definitions investigated the potential bias for any reason other than relapse. First, all patients who withdrew from the study for reasons other than relapse were assumed not to have had a relapse. Second, patients who had a relapse, including patients who were withdrawn because the investigator advised that the patient's safety or wellbeing could be compromised by further participation in the study and patients who received prohibited medication, were compared with those without a relapse, including those who were withdrawn for any other reasons. Third, patients with a relapse were compared with those without a relapse, excluding those who were withdrawn from the study. ${ }^{20}$ We also did two time-to-event analyses and derived Kaplan-Meier estimates. In the first, we considered patients who withdrew or relapsed to have reached the primary endpoint; in the second, withdrawals for reasons other than relapse contributed to a censored primary outcome. We did between-group comparisons using the

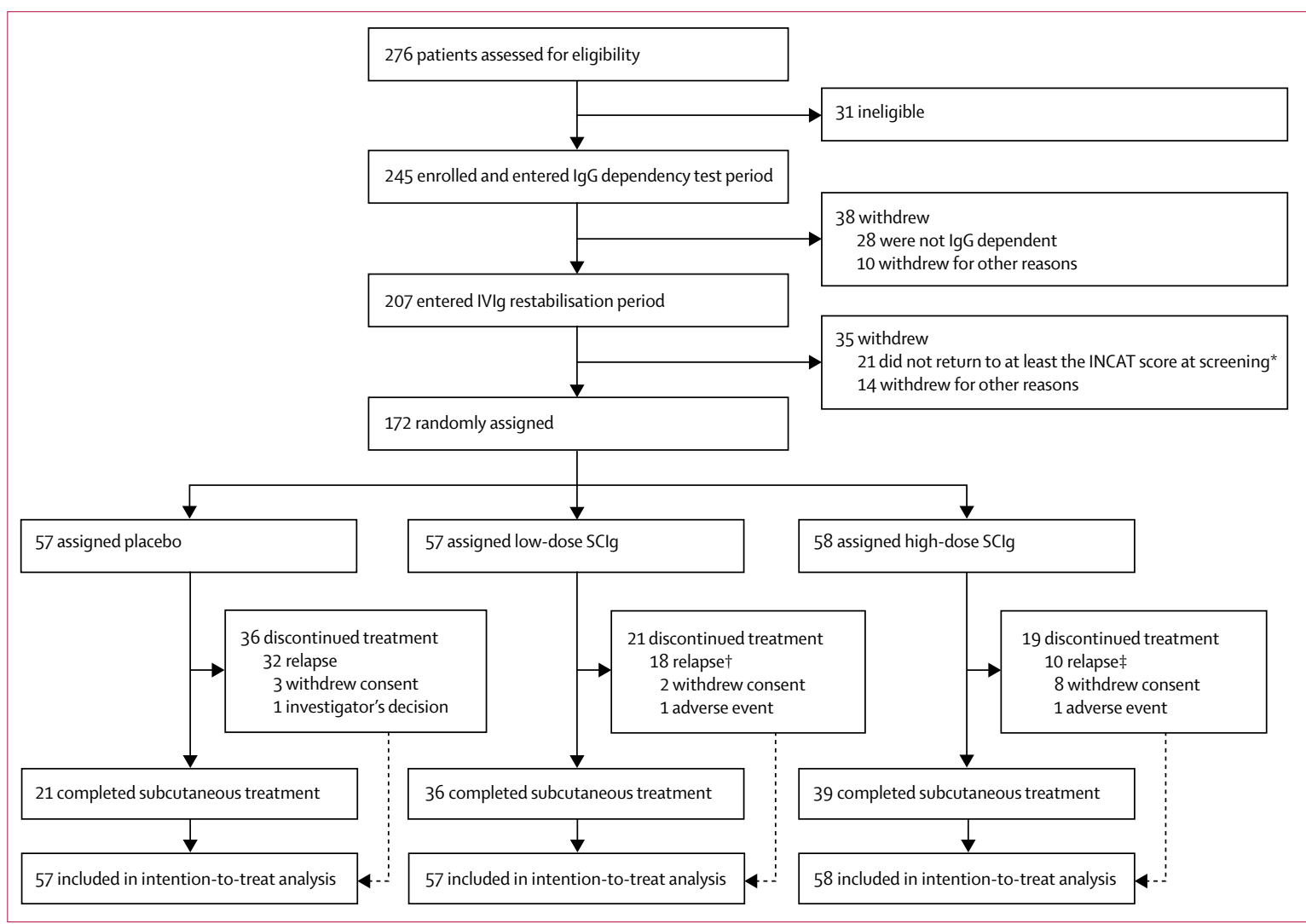

Figure 1: Trial profile

INCAT=Inflammatory Neuropathy Cause and Treatment. SCIg=subcutaneous immunoglobulin. *An additional patient did not return to at least the INCAT score at screening, but was randomly allocated in error. †One patient relapsed at the end of study visit, but was not discontinued, so the total number of patients with a relapse in the low-dose group was 19 . $¥$ One patient relapsed at the end of study visit, but discontinued the study because of an adverse event, so the total number of patients with a relapse in the high-dose group was 11. 
log-rank test for trend. When an overall trend was shown, we did subsequent pairwise one-sided comparisons using the log-rank test.

We present secondary endpoints as median changes from baseline and compare them between the three groups using the asymptotic Jonckheere-Terpstra test. ${ }^{27} \mathrm{We}$ did pairwise comparisons on the basis of median changes from baseline using one-sided Wilcoxon rank sum tests. We accounted for multiple testing for the primary analysis by using a closed testing procedure. All other comparisons are not adjusted and therefore considered exploratory.

The primary outcome was assessed in the intention-totreat and per-protocol sets. ${ }^{21}$ Secondary endpoints were assessed in the intention-to-treat set. Safety was assessed in the safety dataset, including all randomly allocated patients who received at least one dose of study drug. We calculated the rate per infusion as the number of events divided by the overall number of infusions in the respective treatment groups.

During the trial, the protocol was amended five times (appendix). Two changes were made to increase recruitment: amendment 3 introduced two other measures to define IgG dependency (grip strength and I-RODS) and amendment 4 deleted one inclusion criterion, reducing the length of time required for prestudy IVIg from 9 months to 8 weeks. As a consequence of amendment 3, we increased the sample size from 150 to 174. Approximately half of the study population was recruited after amendment 3. 40 patients who were recruited met the newly introduced criteria. We introduced amendment 1 before the study started recruitment, no patients were enrolled under amendment 2 because all amendment 2 changes were incorportated into amendment 3, and amendment 5 was an update to insert new safety language. ${ }^{21}$

The study was overseen by an independent data and safety monitoring board, which did an unmasked formal interim analysis for futility on the basis of the outcome data of 60 patients completing 3 months of treatment. This trial is registered with ClinicalTrials.gov, number NCT01545076.

\section{Role of the funding source}

The funder of the study together with a steering committee was responsible for the design of the trial and the data analysis and contributed to data interpretation and writing of the report. A statistician (NvG) was a member of the steering committee and critically reviewed all results. The funder had no role in data collection. All authors had full access to all data in the study and the corresponding author had final responsibility for the decision to submit for publication.

\section{Results}

Between March 12, 2012, and Sept 20, 2016, we studied patients from 69 neuromuscular centres in North America, Europe, Israel, Australia, and Japan, with the last patient visit on Sept 20, 2016. We screened 276 patients (figure 1). Of these, 245 (89\%) entered the IgG dependency test period. $28(11 \%)$ patients were considered not IgG dependent and nine (4\%) withdrew for other reasons. One $(<1 \%)$ additional patient who was IgG dependent withdrew consent before IgPro10 dosing. 22 (11\%) of the 207 patients who received IgPro10 were not restabilised after a maximum of 13 weeks and were withdrawn (4-week post-study follow-up information was obtained in 16 [73\%] of these 22 patients, revealing that nine [56\%] eventually restabilised). Fourteen (7\%) withdrew for other reasons. $172(83 \%)$ patients were randomly allocated and received treatment: 57 (33\%) patients were assigned to placebo, 57 (33\%) to low-dose SCIg, and 58 (34\%) to highdose SCIg. All 172 randomly allocated patients received their allocated treatment and 5722 (>99\%) of 5739 planned volumes were actually administered. Patients tolerated volumes of up to $50 \mathrm{~mL}$ per injection site, with two to eight infusion sites running in parallel and an infusion rate of up to $50 \mathrm{~mL} / \mathrm{h}$ per site (six patients); maximum total infusion volume was $140 \mathrm{~mL}$, which was applied in two patients. Infusion time was approximately $1 \mathrm{~h}$. No patients were lost to follow-up. Table 1 shows the baseline characteristics. Patients in the three groups were similar in demographic, clinical, disability-related, disease-related, and treatment-related characteristics at baseline, except for sex, with more men in the low-dose group than in the high-dose group and placebo group.

During subcutaneous treatment, 77 (45\%) patients had a CIDP relapse or were withdrawn from the study:

\begin{tabular}{|c|c|c|c|}
\hline & $\begin{array}{l}\text { Placebo } \\
(n=57)\end{array}$ & $\begin{array}{l}\text { Low-dose SClg } \\
(\mathrm{n}=57)\end{array}$ & $\begin{array}{l}\text { High-dose SClg } \\
(\mathrm{n}=58)\end{array}$ \\
\hline Men & $37(65 \%)$ & $42(74 \%)$ & $31(53 \%)$ \\
\hline Age (years) & $57 \cdot 6(46 \cdot 7-65 \cdot 9)$ & $58 \cdot 9(50 \cdot 5-66 \cdot 5)$ & $55 \cdot 2(49 \cdot 2-66 \cdot 4)$ \\
\hline Bodyweight (kg) & $86 \cdot 5(73 \cdot 5-98 \cdot 0)$ & $80 \cdot 0(72 \cdot 0-93 \cdot 0)$ & $80 \cdot 0(60 \cdot 3-96 \cdot 0)$ \\
\hline $\operatorname{BMI}\left(\mathrm{kg} / \mathrm{m}^{2}\right)$ & $28 \cdot 4(24 \cdot 5-30 \cdot 9)$ & $26 \cdot 4(24 \cdot 4-29 \cdot 3)$ & $26 \cdot 6(22 \cdot 6-29 \cdot 2)$ \\
\hline Duration of disease (years) & $2 \cdot 7(1 \cdot 1-4 \cdot 7)$ & $2 \cdot 8(1 \cdot 4-5 \cdot 0)$ & $3 \cdot 3(1 \cdot 3-8 \cdot 6)$ \\
\hline \multicolumn{4}{|l|}{ EFNS/PNS criteria } \\
\hline Definite & $53(93 \%)$ & $51(89 \%)$ & $53(91 \%)$ \\
\hline Probable & $4(7 \%)$ & $6(11 \%)$ & $5(9 \%)$ \\
\hline $\begin{array}{l}\text { Patients with } \geq 4 \mathrm{IVIg} \text { treatments in } 9 \text { months } \\
\text { before enrolment }\end{array}$ & $51(89 \%)$ & $52(91 \%)$ & $54(93 \%)$ \\
\hline IVlg dose during 3 months before screening (g/kg) & $2 \cdot 3(1 \cdot 3-3 \cdot 4)$ & $2 \cdot 3(1 \cdot 3-3 \cdot 0)$ & $2 \cdot 7(1 \cdot 3-3 \cdot 4)$ \\
\hline INCAT disability scale (possible range $0-10)^{*}$ & $2 \cdot 0(1 \cdot 0-3 \cdot 0)$ & $2 \cdot 0(1 \cdot 0-3 \cdot 0)$ & $2 \cdot 0(1 \cdot 0-3 \cdot 0)$ \\
\hline I-RODS (possible range 0-100)† & $68 \cdot 0(51 \cdot 0-83 \cdot 0)$ & $63 \cdot 0(51 \cdot 0-73 \cdot 0)$ & $69 \cdot 0(54 \cdot 0-80 \cdot 0)$ \\
\hline $\begin{array}{l}\text { Grip strength dominant hand ( } \mathrm{kPa} \text {; possible } \\
\text { range } 0-160)\end{array}$ & $68 \cdot 0(49 \cdot 3-83 \cdot 7)$ & $67 \cdot 0(56 \cdot 7-86 \cdot 2)$ & $68 \cdot 4(46 \cdot 0-93 \cdot 3)$ \\
\hline MRC sum score (possible range $0-80$ ) $\ddagger$ & $76 \cdot 0(72 \cdot 0-78 \cdot 0)$ & $75 \cdot 0(70 \cdot 0-78 \cdot 0)$ & $76 \cdot 0(70 \cdot 0-79 \cdot 0)$ \\
\hline
\end{tabular}

Data are $\mathrm{n}(\%)$ or median (IQR). SClg=subcutaneous immunoglobulin. BMI=body-mass index. EFNS/PNS=European Federation of Neurological Societies/Peripheral Nerve Society. IVIg=intravenous immunoglobulin. INCAT=Inflammatory Neuropathy Cause and Treatment. I-RODS=Inflammatory Neuropathy-Rasch-Built Overall Disability Scale. MRC=Medical Research Council. *Larger values indicate greater limitation. †Ranges from 0 indicating most severe activity and social participation limitations to 100 if a patient is fully able. Data missing for 11 patients in the placebo group, six in the low-dose group, and three in the high-dose group. ‡Larger score indicates greater strength

Table 1: Baseline characteristics 


\begin{tabular}{|c|c|c|c|c|c|c|c|c|c|c|}
\hline & \multirow[t]{2}{*}{ Placebo } & \multirow[t]{2}{*}{ Low-dose SClg } & \multirow[t]{2}{*}{ High-dose SClg } & \multirow[t]{2}{*}{$\begin{array}{l}\text { Overall } \\
p \text { value }\end{array}$} & \multicolumn{2}{|c|}{ Low-dose SClg vs placebo } & \multicolumn{2}{|c|}{ High-dose SClg vs placebo } & \multicolumn{2}{|c|}{$\begin{array}{l}\text { High-dose SClg vs } \\
\text { low-dose SClg }\end{array}$} \\
\hline & & & & & Difference & p valuet & Difference & p value $\dagger$ & Difference & $\mathrm{p}$ value $\dagger$ \\
\hline \multicolumn{11}{|c|}{ Intention to treat } \\
\hline $\begin{array}{l}\text { Number of } \\
\text { patients }\end{array}$ & $\begin{array}{l}36(63 \%[50 \text { to } 74] ; \\
n=57\end{array}$ & $\begin{array}{l}22(39 \%[27 \text { to } 52]) ; \\
\mathrm{n}=57\end{array}$ & $\begin{array}{l}19(33 \%[22 \text { to } 46]) ; \\
n=58\end{array}$ & 0.0007 & $\begin{array}{c}-25 \% \\
(-41 \text { to }-6)\end{array}$ & 0.007 & $\begin{array}{c}-30 \% \\
(-46 \text { to }-12)\end{array}$ & 0.001 & $\begin{array}{c}-6 \% \\
(-23 \text { to } 11)\end{array}$ & $0 \cdot 32$ \\
\hline \multicolumn{11}{|c|}{ Per protocol } \\
\hline $\begin{array}{l}\text { Number of } \\
\text { patients }\end{array}$ & $\begin{array}{l}33(63 \%[50 \text { to } 75] ; \\
n=52\end{array}$ & $\begin{array}{l}21(39 \%[27 \text { to } 52] ; \\
\mathrm{n}=54\end{array}$ & $\begin{array}{l}12(26 \%[15 \text { to } 40]) ; \\
\mathrm{n}=47\end{array}$ & $<0.0001$ & $\begin{array}{c}-25 \% \\
(-41 \text { to }-6)\end{array}$ & 0.01 & $\begin{array}{c}-38 \% \\
(-54 \text { to } 18)\end{array}$ & 0.0001 & $\begin{array}{c}-13 \% \\
(-30 \text { to } 5)\end{array}$ & 0.11 \\
\hline \multicolumn{11}{|c|}{ Relapse analysis $\ddagger$} \\
\hline $\begin{array}{l}\text { Number of } \\
\text { patients }\end{array}$ & $\begin{array}{l}32(56 \%[43 \cdot 3 \text { to } \\
68 \cdot 2]) ; n=57\end{array}$ & $\begin{array}{l}19(33 \%[22 \text { to } 46]) \\
n=57\end{array}$ & $\begin{array}{l}11(19 \%[11 \text { to } 31]) \\
\mathrm{n}=58\end{array}$ & $<0.0001$ & $\begin{array}{c}-23 \% \\
(-39 \text { to } 5)\end{array}$ & 0.01 & $\begin{array}{c}-37 \% \\
(-52 \text { to }-20)\end{array}$ & $<0.0001$ & $\begin{array}{c}-14 \% \\
(-30 \text { to } 2)\end{array}$ & 0.06 \\
\hline \multicolumn{11}{|c|}{ Mixed-case analysis $\S$} \\
\hline $\begin{array}{l}\text { Number of } \\
\text { patients }\end{array}$ & $\begin{array}{l}34(60 \%[47 \text { to } 71]) \\
n=57\end{array}$ & $\begin{array}{l}19(33 \%[22 \text { to } 46]) \\
n=57\end{array}$ & $\begin{array}{l}14(24 \%[15 \text { to } 37]) ; \\
n=58\end{array}$ & $<0.0001$ & $\begin{array}{l}-26 \% \\
(-42 \text { to }-8)\end{array}$ & 0.004 & $\begin{array}{c}-36 \% \\
(-50 \text { to }-18)\end{array}$ & 0.0001 & $\begin{array}{c}-9 \% \\
(-25 \cdot \text { to } 7)\end{array}$ & 0.19 \\
\hline \multicolumn{11}{|c|}{ Complete case analysis $₫$} \\
\hline $\begin{array}{l}\text { Number of } \\
\text { patients }\end{array}$ & $\begin{array}{l}32(60 \%[47 \text { to } 72]) \\
\mathrm{n}=53\end{array}$ & $\begin{array}{l}19(35 \%[24 \text { to } 49]) \\
\mathrm{n}=54\end{array}$ & $\begin{array}{l}11(22 \%[13 \text { to } 35]) \\
\mathrm{n}=50\end{array}$ & $<0.0001$ & $\begin{array}{c}-25 \% \\
(-42 \text { to }-6)\end{array}$ & 0.008 & $\begin{array}{l}-38 \% \\
(-19 \cdot 5 \text { to }-20)\end{array}$ & $<0.0001$ & $\begin{array}{c}-13 \% \\
\text { (-29 to } 4)\end{array}$ & $0 \cdot 10$ \\
\hline \multicolumn{11}{|c|}{ 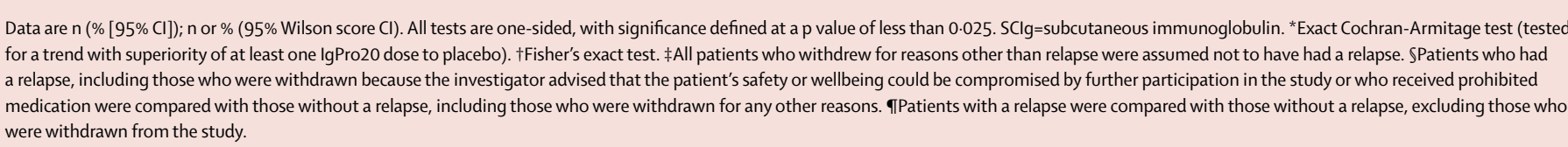 } \\
\hline
\end{tabular}

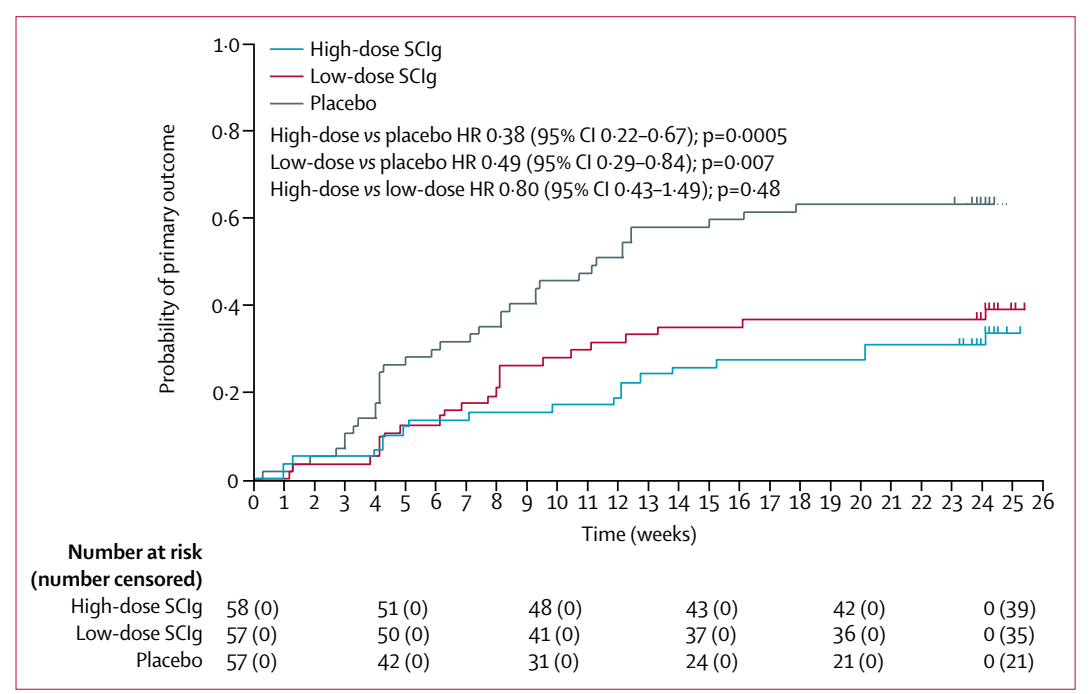

Figure 2: Time to reach primary endpoint

Tickmarks denote censored patients. $\mathrm{HR}=$ hazard ratio. $\mathrm{SClg}=$ subcutaneous immunoglobulin.

36 (63\% [95\% CI 50-74]) in the placebo group, 22 (39\% [27-52]) in the low-dose group, and 19 (33\% [22-46]) in the high-dose group (Cochran-Armitage trend test $\mathrm{p}=0 \cdot 0007$; table 2). The absolute risk reduction (ARR) for reaching the primary endpoint was $25 \%(6-41)$ in the low-dose group $(\mathrm{p}=0.007)$ and $30 \%(12-46)$ in the highdose group $(\mathrm{p}=0.001)$ as compared with placebo. Comparing low dose with high dose, the ARR was $6 \%(-11$ to $23 ; \mathrm{p}=0 \cdot 32)$. The sensitivity analyses showed that the patients who withdrew for reasons other than relapse did not influence the primary endpoint outcome.
$47(81 \%)$ of 58 patients in the high-dose group and $38(67 \%)$ of 57 in the low-dose group remained relapse free (relapse sensitivity analysis).

The probability of reaching the primary endpoint was significantly lower in both SCIg groups than in the placebo group (figure 2, table 3 ). We did a complementary time-to-relapse analysis censoring all withdrawals at the time of withdrawal: both SCIg doses were better than placebo. Both IgPro20 doses were associated with lower relapse rates as compared with placebo (table 3 ) and the probability of a relapse was lower at all timepoints between week 3 and week 25 of subcutaneous treatment in patients receiving IgPro20 when compared with those receiving placebo (figure 2). Using results for probability of relapse by 24 weeks (table 3), the probability of remaining relapse free was estimated to be $77.6 \%$ in the high-dose group, $65.0 \%$ in the low-dose group, and $41.2 \%$ in the placebo group. The number needed to treat (NNT) to prevent one relapse was 2.7 for high-dose IgPro20 and 4.4 for lowdose IgPro20. All per-protocol analyses supported the results of the intention-to-treat analysis (table 2).

$16(9 \%)$ patients withdrew for reasons other than relapse during subcutaneous treatment (four [7\%] in the placebo group, three [5\%] in the low-dose group, and nine [16\%] in the high-dose group): two (1\%) patients withdrew for adverse events (one [2\%] each in the low-dose group and high-dose group; one [2\%] event related to subcutaneous treatment in the low-dose group); 13 (8\%) patients withdrew consent (three [5\%] in the placebo group, two [4\%] in the low-dose group, and eight [14\%] in the high-dose group); and one (2\%) was withdrawn by physician decision (in the placebo group; figure 1). Subsequent investigation after 
database lock revealed that six $(3 \%)$ patients withdrew consent because of issues with subcutaneous infusions (three [all in the high-dose group] for mild local reactions, two [one in the low-dose group and one in the placebo group] did not feel comfortable with the subcutaneous technique, and one [in the high-dose group] no longer wanted to participate because of a need to travel abroad).

$62(36 \%)$ patients relapsed after randomisation (32 [56\%] in the placebo group vs 19 [33\%] in the low-dose group vs 11 [19\%] in the high-dose group; figure 1), of whom $56(90 \%)$ were treated with rescue IgPro10 (32 [57\%] vs 16 [29\%] vs eight [14\%]): 23 (41\%) patients received one induction dose (standard rescue protocol before protocol amendment 3: 12 [52\%] vs six [26\%] vs five [22\%]) and $33(59 \%)$ received one induction dose and up to four maintenance doses (standard rescue protocol after protocol amendment 3: 20 [61\%] vs ten [30\%] vs three [9\%]). Patients were then discontinued from the main PATH study to continue either with the extension study or with their standard-of-care treatment. $23(70 \%)$ of 33 patients who received more than one IgPro10 dose recovered (returned to at least baseline INCAT score; assessed at last study visit), which was similar to the recovery rate based solely on adjusted INCAT score during the restabilisation period (151 [73\%] of 207 patients).

Median changes from baseline in secondary outcome variables showed similar patterns to the primary outcome across the different treatment groups (table 4). All median changes in the high-dose and low-dose groups were significantly better than with placebo except for

\begin{tabular}{|c|c|c|c|c|c|c|c|c|c|c|}
\hline & \multirow[t]{2}{*}{ Placebo } & \multirow[t]{2}{*}{ Low-dose SClg } & \multirow[t]{2}{*}{ High-dose SClg } & \multirow[t]{2}{*}{$\begin{array}{l}\text { Overall } \\
\text { p value* }\end{array}$} & \multicolumn{2}{|c|}{ Low-dose SClg vs placebo } & \multicolumn{2}{|c|}{ High-dose SClg vs placebo } & \multicolumn{2}{|c|}{$\begin{array}{l}\text { High-dose SClg vs low- } \\
\text { dose SClg }\end{array}$} \\
\hline & & & & & Hazard ratio & $\mathrm{p}$ value $†$ & Hazard ratio & p value $\dagger$ & Hazard ratio & p value $\dagger$ \\
\hline Primary outcome & $\begin{array}{l}63 \cdot 2 \% \\
(50 \cdot 9-75 \cdot 4)\end{array}$ & $\begin{array}{l}39 \cdot 0 \% \\
(27 \cdot 7-53 \cdot 1)\end{array}$ & $\begin{array}{l}33 \cdot 7 \% \\
(22 \cdot 8-47 \cdot 8)\end{array}$ & 0.0002 & $\begin{array}{l}0.49 \\
(0.29-0.84)\end{array}$ & 0.007 & $\begin{array}{l}0.38 \\
(0.22-0.67)\end{array}$ & 0.0005 & $\begin{array}{l}0.80 \\
(0 \cdot 43-1 \cdot 49)\end{array}$ & 0.48 \\
\hline Relapse & $\begin{array}{l}58 \cdot 8 \% \\
(46 \cdot 1-72 \cdot 0)\end{array}$ & $\begin{array}{l}35 \cdot 0 \% \\
(23 \cdot 9-49 \cdot 3)\end{array}$ & $\begin{array}{l}22 \cdot 4 \% \\
(12 \cdot 9-37 \cdot 2)\end{array}$ & $<0.0001$ & $\begin{array}{l}0.48 \\
(0.27-0.85)\end{array}$ & 0.009 & $\begin{array}{l}0.25 \\
(0.12-0.49)\end{array}$ & $<0.0001$ & $\begin{array}{l}0.53 \\
(0.25-1.12)\end{array}$ & 0.09 \\
\hline
\end{tabular}

\begin{tabular}{|c|c|c|c|c|c|c|c|c|c|c|}
\hline & \multirow[t]{2}{*}{$\begin{array}{l}\text { Placebo } \\
(n=57)\end{array}$} & \multirow[t]{2}{*}{$\begin{array}{l}\text { Low-dose SClg } \\
(n=57)\end{array}$} & \multirow[t]{2}{*}{$\begin{array}{l}\text { High-dose SClg } \\
(n=58)\end{array}$} & \multirow[t]{2}{*}{$\begin{array}{l}\text { Overall } \\
\text { p value* }\end{array}$} & \multicolumn{2}{|c|}{$\begin{array}{l}\text { Low-dose SClg vs } \\
\text { placebo }\end{array}$} & \multicolumn{2}{|c|}{$\begin{array}{l}\text { High-dose SClg vs } \\
\text { placebo }\end{array}$} & \multicolumn{2}{|c|}{$\begin{array}{l}\text { High-dose SClg vs } \\
\text { low-dose SClg }\end{array}$} \\
\hline & & & & & Difference & p valuet & Difference & p valuet & Difference & $\mathrm{p}$ value $\dagger$ \\
\hline \multicolumn{11}{|l|}{ INCAT (total score) } \\
\hline Last postdose observation & $3.0(3 \cdot 0$ to $4 \cdot 0)$ & $3.0(2.0$ to 4.0$)$ & $2.0(1.0$ to 3.0$)$ & .. & .. & .. & .. & .. & .. &.. \\
\hline Change from baseline & $1.0(0.0$ to 2.0$)$ & $0.0(0.0$ to 1.0$)$ & $0.0(0.0$ to 0.0$)$ & $<0.0001$ & $\begin{array}{l}0.0 \\
(-1.0 \text { to } 0.0)\end{array}$ & 0.0046 & $\begin{array}{l}-1 \cdot 0 \\
(-1 \cdot 0 \text { to } 0 \cdot 0)\end{array}$ & $<0.0001$ & $\begin{array}{l}0.0 \\
(0.0 \text { to } 0.0)\end{array}$ & $0 \cdot 10$ \\
\hline \multicolumn{11}{|l|}{ I-RODS (centile score) } \\
\hline Last postdose observation & $60.0(45.0$ to $69 \cdot 0)$ & $61.0(55 \cdot 0$ to $69 \cdot 0)$ & $65 \cdot 0(52 \cdot 0$ to $80 \cdot 0)$ & .. &.. & .. & .. & .. & .. &.. \\
\hline Change from baseline & $-3 \cdot 0(-16 \cdot 0$ to $0 \cdot 0)$ & $-2 \cdot 0(-7 \cdot 0$ to $2 \cdot 0)$ & $0.0(-2.0$ to 3.5$)$ & 0.0002 & $\begin{array}{l}3.0 \\
(0.0 \text { to } 9.0)\end{array}$ & 0.03 & $\begin{array}{l}5 \cdot 0 \\
(2 \cdot 0 \text { to } 9 \cdot 0)\end{array}$ & 0.0002 & $\begin{array}{l}2.0 \\
(0.0 \text { to } 4.0)\end{array}$ & 0.04 \\
\hline \multicolumn{11}{|c|}{ Grip strength (dominant hand [ $\mathrm{kPa}]$ ) } \\
\hline Last postdose observation & $62 \cdot 0(36 \cdot 0$ to $75 \cdot 3)$ & $64 \cdot 0(55 \cdot 5$ to $87 \cdot 0)$ & $66 \cdot 7(43 \cdot 3$ to $90 \cdot 7)$ & .. & .. & .. & .. & .. & .. & .. \\
\hline Change from baseline & $-6 \cdot 6(-21 \cdot 6$ to $0 \cdot 3)$ & $-0.6(-8.9$ to 7.0$)$ & $-2 \cdot 7(-6 \cdot 6$ to $2 \cdot 0)$ & 0.0223 & $\begin{array}{l}7.6 \\
(2 \cdot 0 \text { to } 14.0)\end{array}$ & 0.004 & $\begin{array}{l}5 \cdot 7 \\
(0.7 \text { to } 11 \cdot 7)\end{array}$ & 0.01 & $\begin{array}{l}-1 \cdot 7 \\
(-5 \cdot 4 \text { to } 2 \cdot 3)\end{array}$ & $0 \cdot 20$ \\
\hline \multicolumn{11}{|c|}{ Grip strength (non-dominant hand [kPa]) } \\
\hline Last postdose observation & $60 \cdot 0(37 \cdot 7$ to $73 \cdot 3)$ & $66 \cdot 7(52 \cdot 7$ to $85 \cdot 0)$ & $65 \cdot 2(42 \cdot 0$ to $89 \cdot 0)$ & .. & .. & .. & .. &.. & .. & .. \\
\hline Change from baseline & $-8 \cdot 3(-24 \cdot 7$ to $1 \cdot 7)$ & $-0 \cdot 4(-10 \cdot 3$ to $7 \cdot 0)$ & $-1 \cdot 7(-6 \cdot 0$ to $4 \cdot 6)$ & 0.0026 & $\begin{array}{l}8 \cdot 3 \\
(1 \cdot 7 \text { to } 15 \cdot 0)\end{array}$ & 0.005 & $\begin{array}{l}8 \cdot 3 \\
(2 \cdot 4 \text { to } 15 \cdot 6)\end{array}$ & 0.002 & $\begin{array}{l}0 \cdot 3 \\
(-4 \cdot 1 \text { to } 4 \cdot 9)\end{array}$ & 0.46 \\
\hline \multicolumn{11}{|l|}{ MRC (sum score) } \\
\hline Last postdose observation & $73 \cdot 0(66 \cdot 0$ to $77 \cdot 0)$ & $74.0(67.5$ to 78.0$)$ & $76.0(68.0$ to 80.0$)$ & .. &.. & .. & .. & .. & .. & .. \\
\hline Change from baseline & $-2 \cdot 0(-6 \cdot 0$ to $0 \cdot 0)$ & $0.0(-2.0$ to 2.0$)$ & $0.0(-2.0$ to 1.0$)$ & 0.0026 & $\begin{array}{l}2.0 \\
(1.0 \text { to } 4.0)\end{array}$ & 0.003 & $\begin{array}{l}2.0 \\
(1.0 \text { to } 4.0)\end{array}$ & 0.002 & $\begin{array}{l}0.0 \\
(-1 \cdot 0 \text { to } 1 \cdot 0)\end{array}$ & 0.47 \\
\hline $\begin{array}{l}\text { Data are median (IQR) or media } \\
\text { the secondary endpoints. These } \\
\text { Neuropathy Rasch-Built Overal }\end{array}$ & $\begin{array}{l}5 \% \text { Moses }(\mathrm{I}) \text {. All test } \\
\text { nparisons are therefo } \\
\text { ability Scale. } \mathrm{MRC}=\mathrm{Me}\end{array}$ & cal Research Council. * & mptotic Jonckheere-Ter & rpstra test. & ilcoxon rank-s & $\begin{array}{l}25 \text { (statisti } \\
\text { atory Neur } \\
\text { test. }\end{array}$ & $\begin{array}{l}\text { testing was nc } \\
\text { athy Cause anc }\end{array}$ & . & $\begin{array}{l}\text { nultiple testing } \\
\text { ODS=Inflamm }\end{array}$ & \\
\hline
\end{tabular}


I-RODS score in the low-dose group. We observed no significant differences between the two dose groups. Health-related quality-of-life measures generally showed better outcomes for both SCIg groups than for placebo (appendix). 135 (88\%) patients reported that learning the technique of self-administration was easy (42 [93\%] in the placebo group, 49 [91\%] in the low-dose group, and 44 [80\%] in the high-dose group). 61 (53\%) of 115 patients who received SCIg preferred their current treatment (30 [53\%] in the low-dose group and 31 [53\%] in the highdose group) versus 22 (39\%) of 57 patients who received placebo, whereas $21(18 \%)$ patients receiving SCIg (ten $[18 \%]$ and 11 [19\%]) and $14(25 \%)$ patients receiving placebo preferred their previous IVIg treatment. Reasons for patients preferring weekly SCIg to monthly IVIg included a gain in independence and fewer side-effects. At the last postsubcutaneous dose observation, serum trough IgG concentrations had decreased in the placebo group, remained stable in the low-dose group, and increased in the high-dose group (appendix).

In the placebo group, 21 (37\%) patients had 52 adverse events over 1514 infusions (table 5, appendix). In the low-dose group, 33 (58\%) patients had 158 adverse events over 2007 infusions; in the high-dose group, 30 (52\%) had 114 events over 2218 infusions. Causally related adverse events occurred in $47(27 \%)$ patients (ten [18\%] in the placebo group, 17 [30\%] in the low-dose group, and 20 [35\%] in the high-dose group). All 110 local reactions (occurring in 32 [19\%] patients; seven events in four [7\%] patients in the placebo group, 54 events in 11 [19\%] patients

\begin{tabular}{|c|c|c|c|c|c|c|}
\hline & \multicolumn{2}{|l|}{ Placebo $(n=57)^{*}$} & \multicolumn{2}{|c|}{ Low-dose SClg $(n=57) \dagger$} & \multicolumn{2}{|c|}{ High-dose SClg $(n=58) \ddagger$} \\
\hline & $\begin{array}{l}\text { Patients with an } \\
\text { event (n) }\end{array}$ & Events $(n) \S$ & $\begin{array}{l}\text { Patients with an } \\
\text { event ( } n \text { ) }\end{array}$ & Events $(n) \S$ & $\begin{array}{l}\text { Patients with an } \\
\text { event ( } n)\end{array}$ & Events $(n) S$ \\
\hline Any adverse event (treatment emergent) & $21(37 \%)$ & $52(0.034)$ & $33(58 \%)$ & $158(0.08)$ & $30(52 \%)$ & $114(0.05)$ \\
\hline $\begin{array}{l}\text { General disorders and administration-site } \\
\text { conditions } \boldsymbol{\Phi}\end{array}$ & $6(11 \%)$ & $10(0.007)$ & $16(28 \%)$ & $60(0.03)$ & $18(31 \%)$ & $52(0.02)$ \\
\hline Fatigue & $1(2 \%)$ & $1(<0.001)$ & $5(9 \%)$ & $5(0.002)$ & 0 & 0 \\
\hline Local reactions $\|$ & $4(7 \%)$ & $7(0.005)$ & $11(19 \%)$ & $54(0.03)$ & $17(29 \%)$ & $49(0.02)$ \\
\hline Infusion-site erythema & 0 & 0 & $5(9 \%)$ & $11(0.005)$ & $10(17 \%)$ & $28(0.013)$ \\
\hline Infusion-site swelling & $2(4 \%)$ & $2(0.001)$ & $5(9 \%)$ & $8(0.004)$ & $6(10 \%)$ & $8(0.004)$ \\
\hline Infusion-site induration & $1(2 \%)$ & $1(<0.001)$ & $2(4 \%)$ & $10(0.005)$ & $3(5 \%)$ & $3(0.001)$ \\
\hline Infusion-site warmth & 0 & 0 & 0 & 0 & $3(5 \%)$ & $3(0.001)$ \\
\hline Infusion-site pain & $2(4 \%)$ & $2(0.001)$ & $3(5 \%)$ & $15(0.007)$ & $2(3 \%)$ & $2(<0.001)$ \\
\hline Infusion-site pruritus & 0 & 0 & 0 & 0 & $2(3 \%)$ & $3(0.001)$ \\
\hline Infusion-site extravasation & 0 & 0 & 0 & 0 & $1(2 \%)$ & $1(<0.001)$ \\
\hline Infusion-site mass & $1(2 \%)$ & $1(<0.001)$ & 0 & 0 & $1(2 \%)$ & $1(<0.001)$ \\
\hline Infusion-site haematoma & $1(2 \%)$ & $1(<0.001)$ & $2(4 \%)$ & $2(<0.001)$ & 0 & 0 \\
\hline Infusion-site haemorrhage & 0 & 0 & $1(2 \%)$ & $1(<0.001)$ & 0 & 0 \\
\hline Infusion-site oedema & 0 & 0 & $1(2 \%)$ & $6(0.003)$ & 0 & 0 \\
\hline Infusion-site rash & 0 & 0 & $1(2 \%)$ & $1(<0.001)$ & 0 & 0 \\
\hline Infections and infestations & $8(14 \%)$ & $11(0.007)$ & $13(23 \%)$ & $18(0.009)$ & $6(10 \%)$ & $9(0.004)$ \\
\hline Nasopharyngitis & $1(2 \%)$ & $1(<0.001)$ & $4(7 \%)$ & $6(0.003)$ & $2(3 \%)$ & $2(<0.001)$ \\
\hline Upper respiratory tract infection & $2(4 \%)$ & $2(0.001)$ & $3(5 \%)$ & $3(0.001)$ & $2(3 \%)$ & $2(<0 \cdot 001)$ \\
\hline Urinary tract infection & $3(5 \%)$ & $3(0.002)$ & $1(2 \%)$ & $1(<0.001)$ & 0 & 0 \\
\hline $\begin{array}{l}\text { Musculoskeletal and connective tissue } \\
\text { disorders }\end{array}$ & $4(7 \%)$ & $4(0.003)$ & $10(18 \%)$ & $14(0.007)$ & $6(10 \%)$ & $7(0.003)$ \\
\hline Arthralgia & $1(2 \%)$ & $1(<0.001)$ & $3(5 \%)$ & $4(0.002)$ & $1(2 \%)$ & $1(<0 \cdot 001)$ \\
\hline Back pain & $1(2 \%)$ & $1(<0.001)$ & $3(5 \%)$ & $4(0.002)$ & $1(2 \%)$ & $1(<0.001)$ \\
\hline Pain in extremity & 0 & 0 & $1(2 \%)$ & $1(<0.001)$ & $3(5 \%)$ & $3(<0.001$ \\
\hline Nervous system disorder & $4(7 \%)$ & $6(0.004)$ & $6(11 \%)$ & $9(0.004)$ & $6(10 \%)$ & $7(0 \cdot 003)$ \\
\hline Headache & $2(4 \%)$ & $2(0.001)$ & $4(7 \%)$ & $5(0.002)$ & $4(7 \%)$ & $4(0.002)$ \\
\hline $\begin{array}{l}\text { Injury, poisoning, and procedural } \\
\text { complications }\end{array}$ & $2(4 \%)$ & $2(0.001)$ & $7(12 \%)$ & $16(0.008)$ & $3(5 \%)$ & $4(0.002)$ \\
\hline Fall & 0 & 0 & $3(5 \%)$ & $8(0.004)$ & $1(2 \%)$ & $1(<0 \cdot 001)$ \\
\hline \multicolumn{7}{|c|}{ 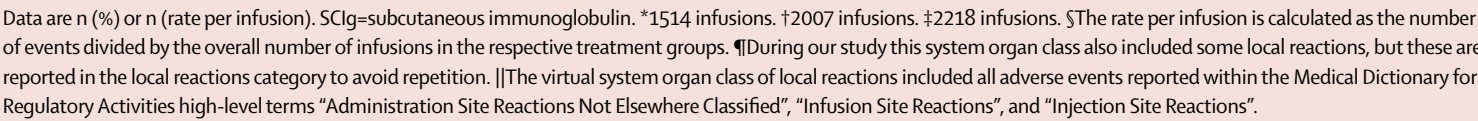 } \\
\hline
\end{tabular}


in the low-dose group, and 49 events in 17 [29\%] patients in the high-dose group) were either mild (104 [95\%]) or moderate (six [5\%]), frequency decreased during the first eight infusions (appendix), and none led to discontinuation. 11 serious adverse events were encountered in six (3\%) patients: one event in one $(2 \%)$ patient who was receiving placebo, five events in three (5\%) patients in the low-dose group, and five events in two (3\%) patients in the highdose group. Only one of those 11 serious adverse events was assessed to be causally related: in the low-dose group, one patient developed an acute allergic skin reaction. This event led to discontinuation of treatment. No haemolysis or thrombosis occurred during the subcutaneous treatment period. Patients using higher infusion rates reported similar proportions of adverse events as those using lower infusion rates (appendix).

\section{Discussion}

This randomised trial in patients with CIDP is, to our knowledge, the largest to date and the first investigating two doses of SCIg in parallel. The study showed that both doses of IgPro20 were efficacious in maintaining stable disease over 24 weeks in patients who were previously shown to be dependent on IVIg treatment. The primary endpoint occured more often in the placebo group than in both SCIg groups. This result was achieved using a conservative endpoint including not only patients who relapsed but also those who were withdrawn for any other reason. $76-81 \%$ of patients in the high-dose group and $65-67 \%$ in the low-dose group remained relapse free in three sensitivity analyses accounting for premature withdrawal of patients with no relapse defined in different ways. These analyses, along with the secondary outcome measures and health-related quality-of-life measures, supported these results, as did the per-protocol analyses. We did not find a large difference in secondary outcomes, possibly because our study was designed to show whether or not IgPro20 could maintain the improvement achieved during the IVIg restabilisation period, and patients were discontinued at the time of relapse to prevent them from deteriorating further. Both doses of IgPro20 were well tolerated when given in high volumes with use of multiple injection sites. Reasons for patients preferring weekly SCIg to monthly IVIg were a gain in independence and fewer side-effects. Local reactions were mostly mild, their frequency was low, and they decreased considerably over time.

Our trial used a unique design. We used an IgG dependency test period to ensure that only patients who were still in need of IgG were randomly allocated. For a trial investigating maintenance treatment in CIDP, the necessity of inclusion of a run-in period in which the IVIg dose is reduced or withheld to prove IgG dependency became clear during the RMC triall ${ }^{28}$ and also from the randomised withdrawal period of the ICE trial, ${ }^{22}$ with most patients in the placebo group not worsening within 24 weeks. During the second phase, patients all received standard doses of IgPro10 to ensure standardised IVIg restabilisation conditions. Each phase had specific rules that had to be fulfilled by a patient to enter the next phase to ensure that all patients were at their best maintenance level before randomisation and assignment to IgPro20 or placebo. We based the IVIg loading and maintenance doses for the restabilisation period on the EFNS/PNS guidelines ${ }^{20}$ and evidence from a large international study. ${ }^{22}$ We designed the study to show whether or not IgPro20 could maintain the improvement achieved during the IVIg restabilisation period.

Our findings are in accordance with several SCIg studies. Two small placebo-controlled randomised trials have been published investigating SCIg in patients with CIDP: the first ${ }^{29}$ included 30 patients who were treated with IVIg and switched to SCIg for 12 weeks; the second ${ }^{30}$ included 19 previously untreated patients. Both showed promising results for impairment, with an increase in muscle strength and improvement in disability. A 1 year open-label follow-up study ${ }^{31}$ has suggested that SCIg could be used as long-term maintenance treatment. Open-label case series and a large prospective observational study have reported clinical efficacy and safety of weekly SCIg. 16,18,32

In patients receiving high-dose IgPro20, the ARR for reaching a relapse only was $37 \%$, with a corresponding NNT of $2 \cdot 7$. A Cochrane Review ${ }^{33}$ of IVIg for CIDP has summarised all trials comparing IVIg with placebo. The review reports that a significantly higher proportion of patients had improved disability within 6 weeks after the onset of treatment with IVIg than with placebo, with a risk reduction of $2.40(95 \% \mathrm{CI}$ $1 \cdot 72-3 \cdot 36)$ and an NNT of $3.03(2 \cdot 33-4 \cdot 55)$. For the parallel design trials only, the risk reduction was $2 \cdot 14$ $(1 \cdot 48-3 \cdot 09)$ and the NNT was $3.33(2 \cdot 38-5 \cdot 88)$. The NNT for SCIg to prevent relapse in this study is therefore in a similar range to the NNT for IVIg found in previous studies.

CIDP guidelines ${ }^{20}$ suggest a maintenance dose for IVIg ranging from $0.4 \mathrm{~g} / \mathrm{kg}$ to $1.2 \mathrm{~g} / \mathrm{kg}$ every 2-6 weeks. This dose would translate into a maximum dose of $0 \cdot 2-0 \cdot 6 \mathrm{~g} / \mathrm{kg}$ every week. In previous studies, weekly doses from $0.1 \mathrm{~g} / \mathrm{kg}$ to $0.4 \mathrm{~g} / \mathrm{kg}$ were administered subcutaneously by converting the intravenous dose $1: 1$ to an equivalent subcutaneous dose. After switching 1:1 from IVIg to SCIg, small dose increases were observed, ranging from $6 \%$ in almost half of patients ${ }^{31}$ to $20 \%$ in a few patients. ${ }^{32}$ In one study $^{17}$ after a follow-up period of 33 months, dose had been increased on average by only $2 \%$ to maintain clinical stability. In our trial, an IVIg dose requirement of more than $1.6 \mathrm{~g} / \mathrm{kg}$ every 4 weeks was an exclusion criterion. The two doses tested in our study $(0.2 \mathrm{~g} / \mathrm{kg}$ and $0.4 \mathrm{~g} / \mathrm{kg}$ weekly) were based on the IVIg maintenance dose recommended by the EFNS/PNS guidelines ${ }^{20}$ for CIDP ( $1 \mathrm{~g} / \mathrm{kg}$ every 3 weeks, equivalent to $0.33 \mathrm{~g} / \mathrm{kg}$ weekly). The high-dose SCIg is thus 21\% higher and the lower dose $39 \%$ lower than this recommended dose. 
Our study has some limitations. First, we did not compare IgPro20 directly with IVIg. A direct comparison needs an inferiority design. We considered this design, but the results of the power calculations meant that we would need an unfeasible number of patients, which makes such a study impossible to complete within an acceptable timeframe. Second, our IgG dependency test was not perfect in the sense that we were able to select only those patients who were IgG dependent. CIDP is a disease with a highly variable disease course and patients have an intrinsic chance of relapsing over time. We know from previous studies that this relapsing occurs in treated and untreated patients, although with treatment chance of relapse can be significantly reduced. ${ }^{22,33}$ In our study, 37\% of IgG-dependent patients (excluding four who discontinued the study for reasons other than adjusted INCAT-defined relapse) on placebo did not relapse. In the ICE trial, ${ }^{22} 15$ (58\%) of 26 patients who responded during the first phase and were randomly allocated to placebo in the second phase did not relapse. The lower non-relapse rate in patients in the placebo group in our trial than in the ICE trial suggests that the IgG dependency test had the intended effect of selecting patients who were still dependent on IgG. Third, a considerable number of patients had missing data for the exploratory outcomes, especially for the preference question. Finally, we did not follow up on patients who were withdrawn for other reasons or rescued during the subcutaneous phase of our trial, apart from patients who entered the extension study. Therefore, we do not know the exact fate of all of those patients.

What are the practical implications of our study? Patients on a standard regimen of IVIg can be safely transitioned to SCIg. Our findings indicate that both SCIg doses are efficacious in maintaining patients with CIDP and preventing relapse. The potential of relapse risk reduction with SCIg is similar to what has been observed in studies of IVIg. We have used SCIg doses that were $21 \%$ higher (high-dose) and 39\% lower (lowdose) than a $1: 1$ conversion of $1 \mathrm{~g} / \mathrm{kg}$ IVIg given every 3 weeks. In accordance with treatment guidelines that recommend individualisation of IgG dose, we suggest that SCIg is given in doses of $0.2-0.4 \mathrm{~g} / \mathrm{kg}$, with the final maintenance dose to be determined on the basis of patient situation, clinical response, and previous IVIg dose and frequency. This large long-term treatment trial of SCIg therefore supports a weekly SCIg dose range of $0 \cdot 2-0 \cdot 4 \mathrm{~g} / \mathrm{kg}$ and shows that SCIg can be used as a maintenance treatment in patients with CIDP.

\section{Contributors}

INvS, VB, H-PH, RAL, GS, OM, DRC, and ISJM conceived and designed the study. J-PL wrote the statistical analysis plan, which was critically reviewed by NvG, BLD, and MP. VB and INvS collected data. INvS, VB, NvG, ISJM, BLD, OM, J-PL, and MP reviewed and analysed data. All authors interpreted data. INvS, VB, NvG, and ISJM drafted the manuscript, which was revised critically by all other authors. All authors read and approved the final manuscript before submission.

\section{PATH study group}

Australia A Sabet, K George (Gold Coast Hospital and Health Service, Southport, QLD). L Roberts, R Carne (St Vincent's Hospital, Melbourne, VIC). S Blum, R Henderson (Royal Brisbane \& Women's Hospital, Herston, QLD). Belgium P Van Damme, J Demeestere (UZ Leuven-Neurologie, Leuven). Canada S Larue, C D'Amour (Hopital Charles LeMoyne, Recherche Sepmus, Greenfield Park, QC). V Bril, A Breiner (Toronto General Hospital, Toronto, ON). Czech Republic P Kunc, M Valis (Neurologicka klinika, Fakultni nemocnice Hradec Kralove, Hradec Kralove). J Sussova, T Kalous (Neurologicka klinika, Vseobecna fakultni nemocnice v Praze, Prague). R Talab, M Bednar (Privatni ordinace neurologie, Hradec Kralove). Estonia T Toomsoo, I Rubanovits (East Tallinn Central Hospital, Tallinn). K Gross-Paju, U Sorro (West Tallinn Central Hospital, Tallinn) Finland M Saarela, M Auranen (Helsinki University Central Hospital, Helsinki). France J Pouget, S Attarian (Hôpital de la Timone Neurologi, Marseille). G Le Masson, A Wielanek-Bachelet (Hôpital Haut-Lévéque, Service de Neurologie Centre hospitalier universitaire de Bordeaux, Bordeaux). C Desnuelle, E Delmont (Hôpital Archet 1 Centre de référence maladies neuromusculaires, Nice). P Clavelou, D Aufauvre (Centre hospitalier universitaire Hôpital Gabriel Montpied, ClermontFerrand). Germany J Schmidt, J Zschuentssch (University Medical Center Goettingen, Goettingen). C Sommer, D Kramer

(Universitaetsklinikum Wurzburg, Wurzburg). O Hoffmann, C Goerlitz (St Josefs-Krankenhaus, Potsdam). J Haas, M Chatzopoulos (Jüdisches Krankenhaus Berlin, Berlin). R Yoon, R Gold (Klinikum der RuhrUniversität Bochum, Bochum). P Berlit, A Jaspert-Grehl (Alfried Krupp Krankenhaus Rüttenscheid, Essen). D Liebetanz, A Kutschenko (GeorgAugust-Universitätsmedizin Göttingen, Göttingen). M Stangel, C Trebst (Medizinische Hochschule Hannover, Hannover). P Baum, F Bergh (Universitaetsklinikum Leipzig, Leipzig). J Klehmet, A Meisel (Klinik und Poliklinik für Neurologie Charité-Universitätsmedizin Berlin, Berlin). F Klostermann, J Oechtering (Charite Universitaetsmedizin Berlin). H Lehmann, M Schroeter (Universitätsklinikum, Köln). T Hagenacker, D Mueller (Universitätsklinikum Essen, Essen). A Sperfeld, F Bethke (Klinikum Ibbenbüren, Ibbenbüren). Israel V Drory, A Algom (Tel Aviv Sourasky Medical Center, Tel Aviv). D Yarnitsky, B Murinson (Rambam Health Care Campus, Haifa). Italy A Di Muzio, F Ciccocioppo (Policlinico SS Annunziata, Chieti Scalo). S Sorbi, S Mata (Ospedaliero Universitaria Careggi, Firenze).

A Schenone, M Grandis (Azienda Ospedaliera Universitaria San Martino di Genova, Genoa). G Lauria, D Cazzato (Fondazione Istituto DiRicovero, Milano). G Antonini, S Morino (Azienda Ospedaliera S Andrea Universita degli Studi di Roma “La Sapienza”, Rome). D Cocito, M Zibetti (Azienda ospedaliero universitaria San Giovanni Battista, Torino). Japan T Yokota, T Ohkubo (Tokyo Medical and Dental University, Tokyo). T Kanda, M Kawai (Yamaguchi University Hospital, Yamaguchi). K Kaida, H Onoue (National Defense Medical Hospital, Saitama). S Kuwabara, M Mori (Chiba University Hospital, Chiba). M Iijima, K Ohyama (Nagoya University Hospital, Nagoya). M Baba, M Tomiyama (Aomori Prefectural Central Hospital, Aomori).

K Nishiyama, T Akutsu (Kitasato University Hospital, Kanagawa). K Yokoyama, K Kanai (Juntendo University Hospital, Tokyo). Netherlands I N van Schaik, F Eftimov (Academic Medical Center, University of Amsterdam, Amsterdam). N C Notermans, N Visser (University Medical Center Utrecht, Utrecht). C Faber, J Hoeijmakers (Maastricht University Medical Center, Limburg). Poland K Rejdak, U Chyrchel-Paszkiewicz (Samodzielny Publiczny Szpital Kliniczny, Lublin). Spain C Casanovas Pons, M Antonia (Universitari de Bellvitge Servicio de Neurología, Barcelona). J Gamez, M Figueras (Hospital Universitario Vall d'Hebron Servicio de Neurología, Barcelona). C Marquez Infante, S Benitez (Hospital Universitario Virgen del Rocío, Seville). UK M Lunn, J Morrow (National Hospital for Neurology and Neurosurgery, London). D Gosal, T Lavin (Salford Royal Hospital, Salford). USA I Melamed, A Testori (IMMUNOe International Research Centers, Centennial, CO). S Ajroud-Driss, D Menichella (Northwestern University Feinberg School of Medicine, Chicago, IL). E Simpson, E Chi-Ho Lai (Methodist Neurological Institute, Houston, TX). M Dimachkie, R J Barohn (University of Kansas Medical Center, Kansas City, KS). S Beydoun, H Johl (University of Southern California Keck School of Medicine, Los Angeles, CA). D Lange, A Shtilbans (Hospital 
for Special Surgery, New York, NY). S Muley, S Ladha (St Josephs Hospital and Medical Center, Phoenix, AZ). M Freimer, J Kissel (Wexner Medical Center at the Ohio State University, Columbus, OH). N Latov, R Chin (Weill Medical College of Cornell University, New York, NY). E Ubogu, S Mumfrey (University of Alabama Medical Center Birmingham, Birmingham, AL). T Rao, P MacDonald (The Neurologic Institute, Charlotte, NC). K Sharma, G Gonzalez (University of Miami, Miami, FL). J Allen, D Walk (University of Minnesota, Clinical and Translational Science Institute, Minneapolis, MN). L Hobson-Webb, K Gable (Duke University Medical Center, Durham, NC)

\section{Independent data and safety monitoring committee}

UK R A C Hughes (chair; Department of Clinical Neuroscience,

King's College London, London). C Frost (Department of Medical Statistics, London School of Hygiene \& Tropical Medicine, London). USA C L Koski (University of Maryland School of Medicine, Department of Neurology, Baltimore, MD). K Gorson (Department of Neurology, St Elizabeth's Medical Center, Tufts University School of Medicine, Boston, MA).

\section{Declaration of interests}

INvS chairs a steering committee for CSL Behring and received departmental honoraria for serving on scientific advisory boards for CSL Behring and Baxter. He received departmental research support from the Netherlands Organization for Scientific Research and Prinses Beatrix Spierfonds. All lecturing and consulting fees for INvS were donated to Stichting Klinische Neurologie, a local foundation that supports research in the field of neurological disorders. He serves on the editorial board of the Cochrane Neuromuscular Disease Group, is a member of the organising committee of the Inflammatory Neuropathy Consortium, a standing committee of the Peripheral Nerve Society, and is a member of the scientific board of the Kreuth III meeting on the optimal use of plasma-derived medicinal products, especially coagulation factors and normal immunoglobulins organised under the auspices of the European Directorate for the Quality of Medicines and HealthCare. VB is a consultant to CSL Behring, Grifols, Union Chimique Belge, Bionevia, and ArgenX. She serves on international scientific advisory boards for the Myasthenia Gravis Foundation of America and Guillain-Barré Syndrome/Chronic Inflammatory Demyelinating Polyneuropathy (CIDP/GBS) Foundation International, and has received research support from CSL Behring, Grifols, Bionevia, Union Chimique Belge, and ArgenX. NvG received departmental honoraria for serving on a scientific advisory board for CSL Behring. H-PH received fees for consulting or serving on steering committees or advertisement boards from Baxter, Bayer Healthcare, Biogen, CSL Behring, Geneuro, Kedrion, Laboratoire francais du Fractionnement et des Biotechnologies, MedImmune, Merck, Novartis, Octapharma, Receptos Celgene, Roche, Sanofi Genzyme, and Teva, with approval by the Rector of Heinrich-Heine-University Düsseldorf. RAL is chair of the Inflammatory Neuropathy Consortium, a standing committee of the Peripheral Nerve Society. He is on the Board of Directors of the Peripheral Nerve Society, is a Medical Advisory Board member of the CIDP/GBS Foundation International, of the Myasthenia Gravis Foundation of America, and of the Myasthenia Gravis Foundation of California, and is a paid consultant for CSL Behring, Novartis, Pharnext, Axelacare, Biotest, and Nufactor. GS served on the scientific advisory boards for the Kanae Science Foundation for the Promotion of Medical Science and Takeda Foundation. He serves on a steering committee for CSL Behring. He received funding for travel and speaker honoraria from Mitsubishi Tanabe Pharma, Shionogi, Bristol-Myers Squibb, Sumitomo Dainippon Pharma, Novartis, Bayer Yakuhin, Pfizer Japan, Boehringer Ingelheim Japan, Kissei Pharmaceutical, Janssen, Teijin Pharma, FP Pharmaceutical, Nihon Pharmaceutical, the Japan Blood Products Organization, Kowa Pharmaceutical, Ono Pharmaceutical, and Eisai. He also received grants from the Ministry of Health, Labour and Welfare Japan, Japanese Ministry of Education, Culture, Sports, Science and Technology, and Japan Society for the Promotion of Science. J-PL is a CSL employee and biostatistician for this study. MP is a CSL employee and biostatistician for this study. OM is a CSL employee and programme director for this study. BLD is a CSL employee and clinical scientist for this study. DRC is a consultant for Acetylon, Alcobra Pharma, Alnylam Pharmaceuticals, Annexon Biosciences, Akros Pharma, Biotest Pharmaceuticals,
Boehringer Ingelheim, Cigna Health Management, CSL Behring, DP Clinical, GlaxoSmithKline, Grifols, Karos Pharmaceuticals, Neurocrine Biosciences, Novartis, Octapharma, Pharnext, Sun Pharmaceuticals, and Syntimmune. He is on the data and safety monitoring board for Pfizer, Johnson \& Johnson, Ionis Pharmaceuticals GlaxoSmithKline, and Axovant Sciences. He has licensed technology for the Total Neuropathy Score for Acetylon, AstraZeneca, Calithera Biosciences, Genentech, Neurocrine Biosciences, Merrimack Pharmaceuticals, Seattle Genetics, and Shire Development Inc. He is on the Board of Directors for the CIDP/GBS Foundation International, Foundation for Peripheral Neuropathy, and Peripheral Nerve Society. ISJM received funding for research from the Talecris Talents programme, CIDP/GBS Foundation International, Prinses Beatrix Spierfonds, and European Union 7th Framework Programme (grant number 602273). Furthermore, a research foundation at the University of Maastricht received honoraria on behalf of him for participation in steering committees of the Talecris ICE Study, Laboratoire francais du Fractionnement et des Biotechnologies, CSL Behring, Novartis, Grifols, and Octapharma. He serves on the editorial board of the Journal of the Peripheral Nervous System, is a member of the Inflammatory Neuropathy Consortium, and is a member of the Peripheral Nerve Society.

\section{Acknowledgments}

This study is funded by CSL Behring. We thank Amgad Shebl and Wilson Hu, CSL Behring safety physicians, for their work and review on ensuring the accuracy of safety data presented in this study.

\section{References}

1 Mathey EK, Park SB, Hughes RA, et al. Chronic inflammatory demyelinating polyneuropathy: from pathology to phenotype. J Neurol Neurosurg Psychiatry 2015; 86: 973-85.

2 Merkies IS, Hughes RA, Donofrio P, et al. Understanding the consequences of chronic inflammatory demyelinating polyradiculoneuropathy from impairments to activity and participation restrictions and reduced quality of life: the ICE study. J Peripher Nerv Syst 2010; 15: 208-15.

3 Rajabally YA. Long-term immunoglobulin therapy for chronic inflammatory demyelinating polyradiculoneuropathy. Muscle Nerve 2015; 51: 657-61.

4 Jolles S, Orange JS, Gardulf A, et al. Current treatment options with immunoglobulin $\mathrm{G}$ for the individualization of care in patients with primary immunodeficiency disease. Clin Exp Immunol 2015; 179: 146-60.

5 Markvardsen LH, Christiansen I, Andersen H, Jakobsen J. Headache and nausea after treatment with high-dose subcutaneous versus intravenous immunoglobulin. Basic Clin Pharmacol Toxicol 2015; 117: 409-12.

6 Markvardsen LH, Christiansen I, Harbo T, Jakobsen J. Hemolytic anemia following high dose intravenous immunoglobulin in patients with chronic neurological disorders. Eur J Neurol 2014; 21: 147-52.

7 Berger M, Jolles S, Orange JS, Sleasman JW. Bioavailability of IgG administered by the subcutaneous route. J Clin Immunol 2013; 33: 984-90.

8 Berger M, Rojavin MA, Kiessling P, Zenker O. Pharmacokinetics of subcutaneous immunoglobulin and their use in dosing of replacement therapy in patients with primary immunodeficiencies. Clin Immunol 2011; 139: 133-41.

9 Berger M. Adverse effects of IgG therapy. J Allergy Clin Immunol 2013; 1: 558-66.

10 Berger M. Choices in IgG replacement therapy for primary immune deficiency diseases: subcutaneous IgG vs. intravenous IgG and selecting an optimal dose. Curr Opin Allergy Clin Immunol 2011; 11: $532-38$.

11 Gardulf A, Nicolay U, Asensio O, et al. Children and adults with primary antibody deficiencies gain quality of life by subcutaneous IgG self-infusions at home. J Allergy Clin Immunol 2004; 114: 936-42.

12 Nicolay U, Kiessling P, Berger M, et al. Health-related quality of life and treatment satisfaction in North American patients with primary immunedeficiency diseases receiving subcutaneous IgG self-infusions at home. J Clin Immunol 2006; 26: 65-72.

13 Gardulf A, Andersen V, Bjorkander J, et al. Subcutaneous immunoglobulin replacement in patients with primary antibody deficiencies: safety and costs. Lancet 1995; 345: 365-69. 
14 Kittner JM, Grimbacher B, Wulff W, Jäger B, Schmidt RE. Patients' attitude to subcutaneous immunoglobulin substitution as home therapy. J Clin Immunol 2006; 26: 400-05.

15 Lazzaro C, Lopiano L, Cocito D. Subcutaneous vs intravenous administration of immunoglobulin in chronic inflammatory demyelinating polyneuropathy: an Italian cost-minimization analysis. Neurol Sci 2014; 35: 1023-34.

16 Cocito D, Paolasso I, Peci E, Spagone E, Lopiano L. Improvement of quality of life in patients with chronic inflammatory demyelinating polyneuropathy shifting from 16 to $20 \%$ subcutaneous immunoglobulins. Neurol Sci 2013; 34: 2061-62.

17 Hadden RD, Marreno F. Switch from intravenous to subcutaneous immunoglobulin in CIDP and MMN: improved tolerability and patient satisfaction. Ther Adv Neurol Disord 2015; 8: 14-19.

18 Racosta JM, Sposato LA, Kimpinski K. Subcutaneous versus intravenous immunoglobulin for chronic autoimmune neuropathies: a meta-analysis. Muscle Nerve 2017; 55: 802-09.

19 Imbach P, Barandun S, d'Apuzzo V, et al. High-dose intravenous gammaglobulin for idiopathic thrombocytopenic purpura in childhood. Lancet 1981; 1: 1228-31.

20 Van den Bergh PY, Hadden RDM, Bouche P, et al. European Federation of Neurological Societies/Peripheral Nerve Society Guideline on management of chronic inflammatory demyelinating polyradiculoneuropathy: report of a joint task force of the European Federation of Neurological Societies and the Peripheral Nerve Society-First Revision. Eur J Neurol 2010; 17: 356-63.

21 van Schaik IN, van Geloven N, Bril V, et al. Subcutaneous immunoglobulin for maintenance treatment in chronic inflammatory demyelinating polyneuropathy (the PATH study): study protocol for a randomized controlled trial. Trials 2016; 17: 345

22 Hughes RA, Donofrio P, Bril V, et al. Intravenous immune globulin ( $10 \%$ caprylate-chromatography purified) for the treatment of chronic inflammatory demyelinating polyradiculoneuropathy (ICE study): a randomised placebo-controlled trial. Lancet Neurol 2008; 7: 136-44.

23 Vanhoutte EK, Latov N, Deng C, et al. Vigorimeter grip strength in CIDP: a responsive tool that rapidly measures the effect of IVIG-the ICE study. Eur J Neurol 2013; 20: 748-55.
24 Kleyweg RP, van der Meché FG, Schmitz PI. Interobserver agreement in the assessment of muscle strength and functional abilities in Guillain-Barré syndrome. Muscle Nerve 1991; 14: 1103-09.

25 van Nes SI, Vanhoutte EK, van Doorn PA, et al. Rasch-built Overal Disability Scale (R-ODS) for immune-mediated peripheral neuropathies. Neurology 2011; 76: 337-45.

26 Atkinson M, Sinha A, Hass S, et al. Validation of a general measure of treatment satisfaction, the Treatment Satisfaction Questionnaire for Medication (TSQM), using a national panel study of chronic disease. Health Qual Life Outcomes 2004; 2: 12.

27 Jonckheere AR. A distribution-free k-sample test against ordered alternatives. Biometrika 1954; 41: 133-45.

28 RMC Trial Group. Randomised controlled trial of methotrexate for chronic inflammatory demyelinating polyradiculoneuropathy (RMC trial): a pilot, multicentre study. Lancet Neurol 2009; 8: $158-64$

29 Markvardsen LH, Debost JC, Harbo T, et al. Subcutaneous immunoglobulin in responders to intravenous therapy with chronic inflammatory demyelinating polyradiculoneuropathy. Eur J Neurol 2013; 20: 836-42

30 Markvardsen LH, Sindrup SH, Christiansen I, et al. Subcutaneous immunoglobulin as first-line therapy in treatment-naive patients with chronic inflammatory demyelinating polyneuropathy: randomized controlled trial study. Eur J Neurol 2017; 24: 412-18.

31 Markvardsen LH, Harbo T, Sindrup SH, et al. Subcutaneous immunoglobulin preserves muscle strength in chronic inflammatory demyelinating polyneuropathy. Eur J Neurol 2014 21: $1465-70$.

32 Cocito D, Merola A, Romagnolo A, et al. Subcutaneous immunoglobulin in CIDP and MMN: a different long-term clinical response? J Neurol Neurosurg Psychiatry 2016; 87: 791-93.

33 Eftimov F, Winer JB, Vermeulen M, de Haan R, van Schaik IN. Intravenous immunoglobulin for chronic inflammatory demyelinating polyradiculoneuropathy. Cochrane Database Syst Rev 2013; 12: CD001797. 